\title{
José Gonçalves da Silva: traficante e tráfico de escravos no litoral norte da Província do Rio de Janeiro, depois da lei de $1850^{12}$
}

\author{
Walter Luiz Carneiro de Mattos Pereira ${ }^{3}$
}

O artigo apresenta a trajetória de José Gonçalves da Silva, submetido ao confisco de parte dos seus bens depois da lei de setembro de 1850. Operando pela micro-história, sem desprezar os contornos do tráfico atlântico e do capital mercantil, esperamos ampliar as visões sobre o comércio ilegal de africanos e seus agentes, tema ainda pouco explorado na historiografia brasileira.

Palavras-chave: Brasil Império - Rio de Janeiro - Tráfico Ilegal de Escravos

José Gonçalves da Silva: the trafficker of slaves and his dealings on the north coast of Rio de Janeiro Province after the law of 1850.

The article gives us the career of Jose Gonçalves da Silva, who experienced the confiscation of part of his property after the law of September 1850. Through microhistory, without neglecting the general outlines of the Atlantic slave trade and merchant capital, we

\footnotetext{
${ }^{1}$ Artigo recebido em junho de 2010 e aprovado para publicação em dezembro de 2010.

${ }^{2}$ Pesquisa em fase inicial, com apoio da Fundação Carlos Chagas de Amparo à Pesquisa no Estado do Rio de Janeiro - FAPERJ. Versões reduzidas deste artigo foram apresentadas no II Congreso Latinoamericano de Historia Económica - Cladhe II, realizado na Cidade do México em fevereiro de 2010 e no POLIS - Laboratório de História Econômica e Social da Universidade Federal Fluminense, em outubro de 2009.

${ }^{3}$ Professor-adjunto de História Econômica do Departamento de Fundamento de Ciências da Sociedade do Instituto de Ciencias da Sociedade e do Desenvolvimento Regional da Universidade Federal Fluminense de Campos dos Goytacazes.E-mail: walterpereira@globo.com
} 
hope to get a broader view of the illegal slave trade and its agents, a relatively unexplored subject in Brazilian historiography.

Keywords: The Empire of Brazil - Rio de Janeiro - Illegal Slave Trade.

José Gonçalves da Silva: le trafiquant et le commerce des esclaves dans la côte du nord de la Province de Rio de Janeiro, après la loi de 1850.

Cet article présente le cas du trafiquant d'esclaves José Gonçalves da Silva, dont les biens ont été confisqués après la loi de 1850. A travers la microhistoire, mais sans négliger les contours du trafic atlantique et du capital marchand, on désire élargir la vision sur le commerce illégal d'esclaves africains et ses acteurs - un sujet encore peu exploité par l'historiographie brésilienne.

Mots-clés: L’Empire du Brésil - Rio de Janeiro - Commerce Ilicite des Africains.

Nos longos anos do tráfico negreiro, os nomes das embarcações registravam uma variedade de títulos que, segundo Jaime Rodrigues, expressava as diversas formas de manifestações da cultura dos homens do mar. Os que tinham algum significado religioso consagravam, na sua maioria, os santos da Igreja Católica, os nomes mais requisitados nos tumbeiros. Mas nem só os santos batizavam esses navios que uniam as margens do Atlântico; Lúcifer também. Inscrita na proa de um barco, essa identificação destoava por ser bastante incomum entre aqueles nomes listados por Rodrigues. ${ }^{4}$ A concepção cristã do avesso do paraíso, ao ser estampada no casco de um navio negreiro, tentava, por certo, reproduzir os cenários de horror das viagens destinadas ao infame comércio. Lúcifer era o nome de um bergantim brasileiro que navegava pelo Oceano Atlântico nos anos finais do tráfico de escravos e que, atingido por "inúmeros contratempos" na costa oeste da África, quando de sua viagem a Zanzibar, foi obrigado a retornar quando tentava ultrapassar o Cabo da Boa Esperança. Seu porto de retorno ao Brasil foi Cabo Frio. A embarcação foi recebida por José Gonçalves da Silva. Coincidência ou não, algum tempo depois o traficante fluminense viveria seu próprio inferno terrestre.

\footnotetext{
${ }^{4}$ Jaime Rodrigues, De costa a costa: escravos, marinheiros, intermediários do tráfico negreiro de Angola ao Rio de Janeiro, São Paulo, Cia. das Letras, 2005 e O infame comércio, Campinas, Unicamp, 2000.
} 
Negociantes de grosso trato, homens de grossa aventura, ${ }^{5}$ comerciantes, capitalistas. Sob essas várias designações, aparecia a força política e econômica daqueles que acumulavam riquezas com o tráfico de africanos para o Brasil e ainda insistiam no comércio ilegal, nos primeiros anos da segunda metade do século XIX. O jogo bruto do governo imperial para pôr fim ao tráfico, submetido às duras pressões da Inglaterra, surtiria efeito, completamente, uma década depois da lei de 4 de setembro de 1850. A questão do tráfico após o fim do tráfico é um tema pouco explorado pela historiografia brasileira. Jaime Rodrigues reforça essa ideia ao falar de um desconhecimento a respeito dos agentes envolvidos no comércio ilegal, notadamente para o período pós-1850.

Negociantes múltiplos, para além do comércio ilegal de africanos, os traficantes constituíam redes de relacionamento dentro e fora do Estado. Mas, também, é possível identificar certa fragilidade dessas redes depois da lei do fim do tráfico, no propósito de manter os privilégios e demais interesses. O caso de José Gonçalves da Silva indica que, para além de tratar-se de um grupo não homogêneo, o destino dos negócios que envolviam esses traficantes parece ter tido colorações distintas. Atipicamente, Gonçalves não seria desterrado, assim como, também de forma atípica, teve confiscados seus bens arrolados nos negócios do tráfico. Por que motivos certas sanções previstas na Lei Euzébio de Queiroz deixariam ou não de serem aplicadas aos senhores do tráfico? Que interesses políticos ou econômicos balizavam essas decisões, ou a história de cada traficante? Devemos buscar indícios e vestígios que perpassam pelas relações sociais vividas por esses negociantes, sem deixar de levar em conta que o tráfico também cultivava uma rede de silêncios.

A trajetória de José Gonçalves da Silva contribui, de forma efetiva, para entender a lógica dos negócios do tráfico após a decretação, sem reservas, de sua extinção. A redução de escala possibilita outra leitura das teias de relacionamento, a partir da trajetória individual de um negocianteltraficante de escravos, cujos limites de uma vida expressa pelas cheganças ao poder e aos privilégios esbarram em prisões e no confisco parcial de seu patrimônio. O mundo de José Gonçalves da Silva passa por uma complexa rede de relações e de espaços distintos que possibilitam ampliar os aspectos relacionados à totalidade da história do ${ }^{5}$ Menção ao título do livro de João Fragoso, Homens de grossa aventura, Rio de Janeiro, Civilização
Brasileira, 2000. 
tráfico atlântico. A pequena escala torna muitas vezes possível a reconstituição do vivido inacessível às outras abordagens historiográficas, permitindo ver as estruturas invisíveis. ${ }^{6}$

Estudar a região norte do litoral fluminense e os arranjos e as estratégias pessoais dos traficantes que ali atuavam implica o reconhecimento de uma análise social mais complexa, pois, ao levar em consideração aspectos singulares, inesperados, multiplicadores da ação coletiva, não significa renunciar a história social ou econômica, mas reforçar e aprofundar seus conceitos. Portanto, cabe investigar e interpretar as reações dos agentes do tráfico, sujeitos à ação repressiva que se impunha àquela atividade ilícita, a partir dos meandros apresentados pelo caso de José Gonçalves da Silva. Analisar as condutas de traficantes/negociantes significa poder nos aproximarmos das fraturas econômicas, sociais e políticas causadas àqueles homens pelo fim do tráfico. Justifica-se, nesse caso, fragmentar, para recompor em seguida. Sabendo que a continuidade do tráfico implicava alto risco, como a perda de prestígio social, de poder local e de substância econômica, José Gonçalves colocava em questão o destino de seus bens, de sua família e o jogo social e político que assegurava sua condição social.

Para as penalidades aplicadas aos traficantes após 1850, as mais graves parecem ser o desterro e o degredo. A menção às penalidades a serem impostas aos envolvidos com o tráfico estava disposta no artigo $4^{\circ}$ da lei de 4 de setembro de 1850, com referências à lei de 7 de novembro de 1831 e ao Código Criminal do Império. Com a pena de expulsão do país, foram atingidos, por exemplo, Vitório Emanuel Paretto (1851); Manoel Pinto da Fonseca, José Bernardino de Sá e Thomaz da Costa Ramos - o Maneta (1852); e Antônio Avellar (1853). Qual o destino do patrimônio e do capital político e econômico desses homens? Alguns puderam retornar como forma de estimular a reprodução de suas fortunas, especula Jaime Rodrigues. Após 1850, os casos de envolvimento no tráfico eram julgados em tribunais especiais, como a Auditoria-Geral da Marinha, em primeira instância, e no Conselho de Estado, em segunda instância, como recurso político. Há, também, o registro de outros traficantes fluminenses que tiveram atuação marcante nesse período, além daqueles mencionados anteriormente, em con-

\footnotetext{
${ }^{6}$ Jacques Revel, Prefácio. In: Giovanni Levi, A herança imaterial: trajetória de um exorcista no Piemonte no século XVII, Rio de Janeiro, Civilização Brasileira, 2000.
} 
junto com aqueles listados por João Oscar: ${ }^{7}$ Faustino Pereira Oliveira, Vicente Espíndola, Nicolau Ventura, Bernardino Pereira Faria Aguiar, Manoel de Souza Guimarães, José Luiz Lopes Trindade (José do Peró), André Gonçalves da Graça, José Antônio de Brito, Joaquim de Abreu da Silva Braga, Manoel Soares, Luiz Mendes Ribeiro, Joaquim Ferramenta, José de Souza Velho, Francisco Domingues Araújo, Aurélio José da Silva Quintaes e Dulfo Desidério da Silva Maya Pessanha.

\section{Negociante, traficante}

No curso do mês de outubro de 1851, foi lançado pela tipografia do Diário do Rio de Janeiro um Libello ao Público ${ }^{8}$ (auto de defesa) para denunciar crimes ocorridos em Cabo Frio, no litoral norte da província do Rio de Janeiro, no primeiro mês daquele mesmo ano. O negociante, homem de grosso trato, fortuna local, traficante, José Gonçalves da Silva, influente na cidade de Cabo Frio e na Corte, denunciara que fora tratado como uma "fera indômita", submetido ao chicote por "altos facínoras" que dominavam a província. Gonçalves fora subtraído de seus armazéns, de seu barracão, de seu trapiche e de demais bens, incluindo escravos. Por fim, tudo lhe fora confiscado e em parte destruído, pelas suas supostas ligações com práticas ilícitas de comércio, pelo trato de africanos. Sentindo-se destruído, Gonçalves julgava-se pelo Libello isento de toda a culpa e iniciava a partir daí um verdadeiro calvário para tentar reconquistar seus bens, depois de julgada sua inocência no processo criminal. A partir do Libello, foram mais 15 anos de publicações em recorrentes Cartas à Nação, em que na maioria das vezes insistia em reafirmar a sua inocência, de forma contundente, engrossando as acusações contra o conselheiro Euzébio de Queiroz, responsabilizando-o pelos seus infortúnios.

Seu drama começaria no dia 20 de janeiro de 1851, quando suas propriedades foram invadidas por policiais da Corte e por soldados da Marinha Imperial

\footnotetext{
${ }^{7}$ João Oscar, Escravidão e engenho: Campos, São João da Barra, Macaé e São Fidelis, Rio de Janeiro, Achiamé, 1985.

${ }^{8}$ José Gonçalves Silva, Acontecimentos em Cabo Frio - Libello ao Público, Rio de Janeiro, Typographia do Diário do Rio de Janeiro, 1851, 45 p. Trata-se de um livreto encontrado em obras gerais, conjunto de "miscelâneas", na Biblioteca Nacional, a partir da indicação no site da FBN, em consulta à documentação relativa à cidade de Cabo Frio.
} 
chefiados por Bernardo Augusto Nascimento Azambuja, chefe de polícia interino da província do Rio de Janeiro, "causando graves prejuízos a esse cidadão brasileiro, não se sabe por que crime”. O vapor D. Affonso deslocou-se até Cabo Frio equipado com 60 praças de imperiais marinheiros e 60 policiais. O chefe de polícia trazia em mãos uma portaria do ministro da Justiça, Euzébio de Queiroz Coutinho Mattoso da Câmara, e pela força se dispunha a "assaltar, destruir e saquear” os bens de José Gonçalves. Assim foi feito por Azambuja, ao invadir suas propriedades, arrombar as gavetas, devassar os segredos de família, tudo isso à mão armada. Seus bens haviam sido confiscados por determinação da "hydra de cem cabeças que ameaça devorar tudo e a todos", referindo-se claramente ao atual conselheiro de Estado, que teria determinado a caçada implacável ao traficante de Cabo Frio.

José Gonçalves da Silva era português da cidade do Porto, tendo chegado ao Rio de Janeiro em 1813. Arrumou-se como caixeiro viajante na Rua do Ouvidor, no 49, na casa de Antônio Pinto Pereira Guimarães, de quem, posteriormente, comprou o estabelecimento. Casou-se, em 12 de setembro de 1829, na Capela de São Cristóvão, na Corte, com Ana Francisco Moreira da Silva, natural do Rio de Janeiro. Ana Francisca viria a falecer na mesma cidade, de tuberculose pulmonar, em 11 de junho de 1856. O casal teve três filhos: Augusto Moreira da Silva, morador em Coimbra, onde estudava Direito; Ana Moreira da Silva, moradora em Araruama, casada com Antônio Antunes Moreira, que se tornara o único inventariante dos bens do casal após a morte de sua sogra, em função do afastamento do sogro do processo, por determinação judicial; e Francisca Moreira da Silva, viúva de Felix Antunes Moreira, com quem teve três filhos. Felix era irmão de Antônio, o genro inventariante.

$\mathrm{Na}$ trama de José Gonçalves da Silva, o sobrenome Moreira tem a sua relevância. Certa vez, o traficante de escravos afirmou que seu sogro, de nome João Moreira, era um homem rico. Por coincidência ou não, Moreira também era o sobrenome de seus dois genros, Felix e Antônio. João Oscar, ${ }^{9}$ por exemplo, identifica o português João Baptista Moreira, cônsul de Portugal na Corte, como um dos principais homens envolvidos no tráfico na praça do Rio de Janeiro. Vale lembrar, aqui, a sustentação que faz Gerard Horne do envolvimento do corpo diplomático português em várias cidades atlânticas, de Nova York a Luanda, com

\footnotetext{
${ }^{9}$ João Oscar, op. cit.
} 
os negócios do tráfico de africanos. ${ }^{10}$ Havia, também, o português José Domingues Moreira, com quem Gonçalves realizava negócios. Como sua família tinha estreitas relações de parentesco em Portugal, onde estudava seu único filho, custeado por parentes, depois da derrocada econômica do pai, é preciso prospectar com o propósito de constatar ou não a existência de conexões para além de laços sentimentais entre esse suposto clã, os Moreiras, e José Gonçalves. Tratando-se do envolvimento de portugueses no tráfico de escravos, há fortes indícios. O recurso aos registros paroquiais poderia ajudar a decifrar se a família Moreira reproduzia-se por práticas de endogamia.

Condecorado por Dom Pedro I por sua atuação na Revolta da Artilharia, Gonçalves lutou ao lado do governo em um assalto à fortaleza da Ilha das Cobras, quando soldados da Marinha se sublevaram em outubro de 1831, ano da abdicação do imperador. O negociante, que fora soldado da Imperial Guarda de Honra, adquirira alguns privilégios e títulos, como o de Comendador e o de Cavalheiro da Ordem de Cristo. Merecedor de muitas graças por Pedro I, com quem afirmou ter lutado pela emancipação política do Brasil, Gonçalves se livrara da prisão depois dos episódios de 1850 por conta de tais mercês. Astuto no trato com as autoridades, conseguira fugir da prisão, em Cabo Frio, no dia 15 de fevereiro de 1851, seguindo para Niterói escoltado por alguns homens, pois foi preciso ir "por terra, andando de noite, por causa dos assassinos que meus inimigos tinham posto pelas estradas". Esses detalhes nos chegam porque esses deslocamentos traduziam-se em gastos que o traficante tentava ressarcir, depois de lançados como despesas correntes, quando da abertura do inventário post-mortem de sua esposa. Homem de grandes posses, sua fuga foi facilitada pelo carcereiro da cadeia de Cabo Frio, José Narciso Cruz, que teria recebido 600\$000, pela tarefa e, também, por não ter cumprido a ordem do juiz local, que lhe mandara trancar Gonçalves na "enchova", carregado a ferros. Ao que consta, sua escapada estava relacionada ao temor de ser morto em Cabo Frio, pois, ao chegar à capital da província, entregara-se ao Estado-Maior da Polícia, onde permaneceu preso durante três meses, para depois apresentar-se ao Tribunal do Júri daquela localidade, ficando inocentado do processo penal por envolvimento no tráfico de africanos. O traficante conservara boas relações na cidade, seguro de seus algozes.

${ }^{10}$ Gerard Horne, O sul mais distante: os Estados Unidos, o Brasil e o tráfico de escravos africanos, São Paulo, Cia. das Letras, 2010. 
Há anos Gonçalves estava desprovido dos rendimentos de suas propriedades, abandonadas ou em ruínas depois dos acontecimentos de 1851. Os escravos deixados na propriedade rural de Cabo Frio, de 60 estavam reduzidos a 22, "das cabeças de gado vacum, muar e cavalar só pude contar 200”. Os trapiches, envolvidos no comércio de navegação costeira, "mudaram-se para as repartições do Estado", em uma alusão aos bens confiscados levados ao Arsenal de Marinha do Rio de Janeiro. "Há 12 anos peço justiça, há doze anos escarnecem da minha desgraça."11 Gonçalves responsabilizava o Estado por prejuízos totais que lhe foram causados. Pelas mercadorias apreendidas no trapiche, o montante chegava a 234 contos; por lucros cessantes em função do desmonte do mesmo trapiche, reclamava 54 contos; por prejuízos causados à fazenda de Baía Formosa, em Armação dos Búzios, 194 contos; por rendimentos não auferidos da mesma fazenda, da qual tirava sua subsistência: 12 contos, perfazendo um total de 144 contos nesses 12 anos. Desejava, ainda, receber juros de 625 contos pelo desembolso de recursos próprios que vinha utilizando nesse período, calculados à razão de $6 \%$ ao ano. José Gonçalves apresentou ao império uma fatura robusta do saldo "que até hoje está me devendo o governo do Brasil, 851 contos", um valor considerável, sem contar a soma do seu patrimônio, que não foi arrolada entre os bens confiscados. Uma indenização que, segundo o negociante, o compensaria da destruição, pelo império, de parte de sua fortuna.

Incapaz de influenciar nos destinos do tráfico, após 1850, Gonçalves tentava proteger-se, ao externar o infortúnio causado pela completa demonização de sua pessoa por motivos que não aceitava reconhecer. Sem dúvida, para um homem de suas relações, abastado de bens, colocava-se como trágica a experiência que estava vivendo. Sua condição social, até então, lhe fazia imune aos braços da lei; entretanto, a acusação de tráfico ilegal de escravos caiu sobre ele como uma bomba. Não se cansava de expor as perseguições que dizia sofrer. A partir desse enredo, pelo estudo de trajetórias individuais, como no caso do traficante/negociante José Gonçalves da Silva, é possível traçar linhas sobre um objeto ainda obscuro pela historiografia, privilegiando o local e a unidade de investigação, na tentativa de, como diria Jacques Revel, produzir uma cartografia do social em

\footnotetext{
${ }^{11}$ Carta aberta ao imperador Pedro II. Jornal do Commercio, Rio de Janeiro, 20 de janeiro de 1862.
} 
que os vestígios aí reduzidos contribuem para a análise de interações múltiplas na tentativa de buscar o macro dentro de um jogo de escalas. ${ }^{12}$

Vestígios e indícios, muitas vezes considerados como detalhes secundários ou particularidades insignificantes, podem decifrar pistas na tentativa de remontar uma realidade complexa como o tráfico de escravos no Brasil depois da lei de 1850. Nesse sentido, o historiador pode atribuir-se do saber conjectural, como afirma Carlo Ginzburg, para apropriar-se dos traços individuais de um objeto. ${ }^{13}$ Escritos e discursos podem ser tomados segundo o autor como fios que comportam uma trama densa. Os textos impressos por José Gonçalves da Silva sobre seu irremediável destino, condenado à exclusão social por ser traficante, nos remetem a questões sobre sua trajetória para entender algumas chaves relacionadas ao fim do tráfico negreiro no Brasil. Para Ginzburg, tal escolha não implica abandonar a ideia de totalidade, pois não se abre mão da profunda conexão entre as opacidades da realidade e as zonas privilegiadas que permitem decifrá-las e que revelariam a visão de mundo de determinada classe social ou de uma sociedade. Assim, a partir da trajetória de vida de José Gonçalves, antes e depois de 1850, é possível chegar à compreensão da dimensão que o fim do tráfico colocou para a sociedade brasileira. Cabe ressaltar que o fim do tráfico não significou o fim da escravidão, logo, a condenação moral de José Gonçalves, sob acusações de tal crime, desenvolveu-se em uma sociedade que tolerava a escravidão, embora houvesse sinais de perda de sua legitimidade, sobretudo depois de 1850 .

O inventário dos bens de José Gonçalves da Silva e de sua falecida esposa indicava ser ele um negociante possuidor de riquezas e de abastado patrimônio, perfeitamente inserido na dinâmica do capital mercantil por uma diversidade de atividades ligadas ao comércio e à agricultura, agregando prestígio social e poder. Entretanto, os valores mais expressivos da fortuna do negociante estavam representados pelos montantes dos bens confiscados no trapiche, que se encontravam sub judice. O inventário teve início em 13 de março de 1862, com autos conclusos em 30 de novembro de 1863, e seria posteriormente reaberto em função de irregularidades constatadas por seu genro. Aqui caberia a seguinte questão

\footnotetext{
${ }^{12}$ Jacques Revel, op. cit.

${ }^{13}$ Carlo Ginzburg, Mitos, emblemas e sinais: morfologia e história, São Paulo, Cia. das Letras, 1999, p. 143-179.
} 
para a qual é necessário procurar uma resposta: por que o inventário seria aberto somente seis anos depois do falecimento de sua esposa?

Entre os bens do casal a serem divididos estavam: 1) uma fazenda em Baía Formosa, Armação dos Búzios, com 200 cabeças de gado e plantações de café, milho, feijão, arroz, algodão, produção de farinha de mandioca, engenho, dotada de três casas - avaliada em 10 contos de réis, sem incluir as culturas e os animais; 2) trapiche na barra do Canal de Cabo Frio, próximo ao Forte São Mateus, com 100 braças de testada e 45 de fundos, com armazéns de madeira e porto de embarque. Em seus armazéns e trapiche constavam as seguintes mercadorias: massames, lonas, âncoras, correntes de navios, ancoretas, fateixas, barris de alcatrão, barris de tinta, barris de prego de cobre, peças de cabo, 80 toneladas de carvão de pedra - sem avaliação por estarem sub judice; 3) uma chácara em Cabo Frio, com 120 braças de frente e 400 de fundos, com duas edificações mobiliadas, avaliada em 16 contos; 4) uma chácara no Rio de Janeiro, à Rua Nova do Imperador, nํㅡㄴ (sem avaliação); 5) 63 cativos na fazenda, no trapiche e na chácara, além de outros nove em poder de seus filhos, perfazendo um total de 73 escravos, avaliados em 31 contos, embora José Gonçalves afirmasse que muitos desses cativos encontravam-se alforriados ou fugidos depois da sua prisão; 6) seis apólices da província do Rio de Janeiro, avaliadas em três contos; 7) suas apólices da dívida pública do império, com rendimentos de 6\% ao ano, avaliadas em dois contos; 8) 10 ações do Banco Rural - avaliadas em três contos; e 9) duas ações do Monte Socorro, avaliadas em $200 \$ 000 .{ }^{14} \mathrm{O}$ valor inventariado total dos bens do casal chegava ao montante de 65 contos. Sua chácara no Rio de Janeiro, embora não figurasse no registro de sua avaliação no inventário, parecia ser uma propriedade de valor expressivo, pois pode servir de lastro para garantir, por hipoteca, uma operação de crédito no valor de 20 contos, tomados de José Domingues Moreira, recursos que Gonçalves aplicara em "suprimento de seus negócios", segundo menção feita em escritura lavrada no dia 9 de dezembro de $1850 .{ }^{15}$ Esse empréstimo, de grande vulto, tomado por José Gonçalves três meses depois de decretado o fim do tráfico e um mês antes do confisco de suas propriedades, é sintomático. Não há nenhum

\footnotetext{
${ }^{14}$ Inventário dos bens de José Gonçalves da Silva e Ana Francisca Moreira da Silva. ID 45069, ano 1864, notação 2492 - Arquivo Nacional - caixa 2748.

${ }^{15}$ Hipoteca registrada no 3음 Ofício de Notas do Rio de Janeiro - livro 206, folha 65 - Arquivo Nacional - microfilme 010.15-79.
} 
indício, no inventário, de que tenha adquirido algum bem de valor aproximado; portanto, pode-se especular que esses recursos fossem direcionados ou pudessem ter algum vínculo com atividades relacionadas ao comércio de africanos.

O curso do inventário não foi pacífico. Houve embargos feitos por alguns poucos credores, mas principalmente aqueles feitos por seu próprio genro, Antônio Antunes Moreira, que, dividindo inicialmente a condição de inventariante com José Gonçalves da Silva, passaria a conflitar com seu sogro, em especial pelo fato de haver suspeitas de que Gonçalves estivesse ocultando bens ou de não ter informado, em juízo, aqueles que teriam sido objeto de negociação depois da morte de sua esposa. As suspeitas eram muitas. As apólices da divida pública do império não seriam duas e, sim, 17, posto que algumas delas teriam sido negociadas depois do óbito de sua esposa e outras sete, negociadas, ilegalmente, nos dias 7 de janeiro e 8 de agosto de 1863, durante o processo do inventário. Dessas apólices, oito foram entregues ao visconde de Ipanema, Cesário Pinto de Magalhães, como parte do pagamento referente à compra de um armazém de mantimentos e de carne seca por atacado, situado à Rua Direita, nº 13, no Rio de Janeiro, adquirido em 31 de maio de 1861 por 851 contos de réis, cujas parcelas estavam em atraso, sob cobrança judicial. ${ }^{16}$ Não estava também inclusa no inventário a embarcação Augusta, avaliada em $800 \$ 000$. Outra reclamação expressa por seu genro era quanto à discrepância em relação ao plantel de escravos inscrito no inventário, pois, ao se levar em conta o número de cativos segurados por Gonçalves, na Companhia de Previdência de Seguros, esse total chegaria a 290 homens e mulheres, de várias nações e idades. O montante despendido para o pagamento das apólices de seguro, em 24 de setembro de 1860, chegara ao valor de 11 contos. Para seu genro, os valores segurados seriam incompatíveis com a quantidade de escravos segurados declarada pelo sogro no inventário: 72 .

Registros apresentados por Gonçalves como simples despesas também contribuíram para alimentar desconfianças quanto ao número de cativos, como os valores lançados na rubrica relativa a internações, tratamento e enterros de escravos junto à Casa de Saúde São Sebastião no Rio de Janeiro, no Rocio Pequeno, no 10, e à Santa Casa da Misericórdia. A movimentação da escravaria de José Gonçalves nessas duas instituições era impressionante. Mais curioso ainda era o fato de o negociante "levar" seus escravos até o Rio de Janeiro para receberem cui-

\footnotetext{
${ }^{16}$ Tribunal da Relação do Rio de Janeiro, 1862/3, n. 5098 - Arquivo Nacional - caixa 252, galeria C.
} 
dados médicos. Presume-se que José Gonçalves pudesse manter uma expressiva quantidade de escravos na cidade, com o intuito de negociá-los. Por todas essas artimanhas, o período em que dura o inventário é recheado de desentendimentos entre José Gonçalves da Silva e seu genro Antônio Antunes Moreira. Foram essas desavenças e desconfianças que levaram a Justiça a afastar o negociante do processo. Com o intuito de prestar esclarecimentos sobre possíveis inconsistências apresentadas no inventário, Gonçalves foi intimado a depor em 25 de julho de 1866. O negociante declinara e, por crime de desobediência, fora recolhido, no dia 13 de março de 1867, ao Estado-Maior do Corpo, no Quartel Permanente da Corte, localizado à Rua dos Barbonos. Colocado em uma cela especial, afirmara que tal privilégio, reivindicado por ele, surtiu efeito sob a sua alegação de que fora "soldado de honra do senhor Dom Pedro I".

A análise da base patrimonial de José Gonçalves ajuda a decodificar os negócios ligados ao tráfico de escravos como um empreendimento econômico plural, produtor de uma acumulação interna. Manolo Florentino, ao estudá-lo, lembra tratar-se o tráfico de um negócio não capitalista, marcado por um caráter autônomo em face do capital internacional. ${ }^{17} \mathrm{~A}$ fortuna acumulada por José Gonçalves da Silva, até aqui um desconhecido traficante para a historiografia, mostra a pujança de seus negócios, daquele que ocupava um papel que Florentino defende como ímpar na hierarquia socioeconômica do império. Mesmo assim, é necessário aprofundar os estudos pela decomposição de sua fortuna e ver como ela se dissolve através das suas relações sociais, incluídas as de parentesco.

Dessa maneira, não podemos deixar de considerar que o negociante/traficante em destaque fazia parte de um grupo que influenciava decisivamente os negócios do tráfico, abalado por um golpe mortal dado pela lei de 1850. Esse duro golpe serviu para desnudar o fluxo de capitais que advinha do envolvimento com o tráfico, materializado em seu ostensivo patrimônio e negócios diversos. As atividades nas quais se envolve são correlatas às listadas por Florentino, próximo dos agentes econômicos e financeiros da Corte, homens dados aos riscos e a grandes investimentos: Gonçalves era proprietário de mercados, trapiches, embarcações, escravos, estaleiro, imóveis urbanos e rurais em Cabo Frio e no Rio de Janeiro, títulos da dívida pública etc. Diversificar para lucrar, investir e

${ }^{17}$ Manolo Florentino, Em costas negras: uma história do tráfico entre a África e o Rio de Janeiro, São Paulo, Cia. das Letras, 1997. 
especular. Portanto, José Gonçalves não se afasta do perfil de um negociante/ traficante proposto por Manolo Florentino, cuja trajetória parte de uma base econômica comum às elites mercantis do Rio de Janeiro. A historiografia pouco se deteve nesses homens que traficavam na ilegalidade, por estar mais preocupada em enfatizar os números brutalmente decrescentes da entrada de africanos no Brasil depois de 1850. Esses números, penso eu, não se sustentam em algum registro material, até porque a ilegalidade não permite inventários, a não ser, no limite, de natureza policial ou jurídica. Por outro lado, a pesquisa histórica pode oferecer outras bases de análise e interpretação, a partir da própria manifestação do sujeito como agente do tráfico. Com esse âmago é que João Fragoso aposta na maior atenção ao cotidiano das pessoas que viveram fenômenos ditos econômicos, produzidos em meio à sociedade que os gerou. Fragoso está tentando operar uma historia econômica que integre o micro ao macro. ${ }^{18}$

\section{O tráfico depois do fim do tráfico}

O litoral fluminense foi pontilhado por desembarques de africanos depois de 1850. Sob cabotagem severa dos ingleses em seus portos, as pressões sobre o império do Brasil intensificavam-se cada vez mais. Basta, por exemplo, atentarmos para as determinações frequentes do ministro da Justiça, Euzébio de Queiroz, aos presidentes da província do Rio de Janeiro, entre os anos 1850 e 1854. Um bom indicador é o guia de fontes organizado por Thalita de Oliveira, ${ }^{19}$ dando conta dos comunicados reservados entre o Ministério da Justiça e autoridades provinciais e locais, ou mesmo entre autoridades provinciais e municipais. $\mathrm{Da}$ foz do rio Itabapoana a Angra dos Reis, os negreiros povoavam os termos dos ofícios e diligências a serem feitas por policiais e juízes. Só para ficar no caso de Cabo Frio, encontramos os seguintes registros: em 28 de junho de 1850, pouco antes da assinatura da Lei do Fim do Tráfico, o vice-presidente da província mandara um ofício ao ministro da Justiça comunicando a demissão e a prisão do comandante do Forte São Mateus, acusado de sinalizar aos negreiros, prestando

\footnotetext{
${ }^{18}$ João Fragoso, Para que serve a história econômica? Notas sobre a exclusão social no Brasil, Estudos Históricos, Rio de Janeiro, n. 29, p. 3-28, jan./jul. 2002.

${ }^{19}$ Talita Oliveira (org.), Documentos sobre a repressão ao tráfico de africanos no litoral fluminense, Niterói, Secretaria de Educação e Cultura/Departamento de Difusão Cultural/Biblioteca Pública do Estado, 1966.
} 
auxílio no desembarque. A unidade militar, posteriormente, seria atacada por embarcações inglesas que navegavam em águas fluminenses. Euzébio de Queiroz estava atento aos desembarques em Cabo Frio, como demonstra uma correspondência enviada em 3 de fevereiro de 1851 ao presidente da província para reafirmar o envolvimento de portugueses no tráfico, depois de desarticular os negócios de José Gonçalves. O ministro determinara que os envolvidos fossem alistados no Exército e na Marinha, e que, caso se constatasse o envolvimento de outros estrangeiros, fossem todos alertados que deixassem o litoral da província. Na mesma correspondência, Euzébio de Queiroz revelara a denúncia feita pelo representante do governo britânico sobre a existência de barracões e armazéns envolvidos no tráfico ao longo da costa do Rio de Janeiro, em especial de estaleiros. As determinações recebidas da Corte foram desdobradas em diligência feita pelo juiz de Direito de Cabo Frio, que, depois de vistoriar armazéns locais, confirmou as suspeitas de ligação desses estabelecimentos com o tráfico de africanos. A neutralização aos negócios de José Gonçalves da Silva acentuou a repressão em torno do tráfico na região.

A estratégia do governo provincial, com o apoio do governo central, chegara à organização de uma operação "caça tumbeiros", dotada de uma tropa de 62 homens que percorriam o litoral fluminense de Norte a Sul. As comarcas e as câmaras municipais foram alertadas por diversas portarias e comunicados reservados, pelo menos até 1854 . Por outro lado, a ronda da Marinha britânica era diuturna. Alertas não haviam faltado às autoridades locais e aos comandantes do Forte São Mateus, na entrada da barra do Canal do Itajuru. Havia evidências de que os ingleses municiavam as autoridades brasileiras de informações sobre o envolvimento do comando do Forte em operações ilícitas. De fato, a intervenção britânica se tornaria concreta em 23 de junho de 1850, quando antes ainda da Lei do Fim do Tráfico a cidade de Cabo Frio e sua pequena fortificação foram atacadas pelo vapor de guerra inglês Cormorant. Às cinco horas da tarde, a fragata aproximou-se do Forte e lançou ao mar dois lanchões e uma baleeira, com mais de 50 homens, entre soldados e oficiais ingleses. O prático da operação era um brasileiro, atuando sob autorização do governo imperial. Um dos oficiais trazia em mãos uma bill (referência à Bill Aberdeen, lei britânica de 8 de agosto de 1845), aprovada pelo Parlamento inglês, que autorizava a entrada de embarcações inglesas em qualquer porto para revistar toda e qualquer embarcação que 
lhes conviesse. Enquanto o oficial inglês abordava o comandante do Forte, a baleeira entrara pelo Canal de Cabo Frio, atemorizando o comandante da unidade militar, que "se acovardou de tal modo, não conseguindo sustentar e manter a dignidade da nação, deixou tudo entregue à vontade dos invasores". Os ingleses, então, dirigiram-se à escuna Rival, que estava próximo ao Rancho dos Índios, onde se localizavam o trapiche, o estaleiro e o porto de José Gonçalves, e bombardearam a embarcação, pondo em fuga a tripulação. Vinte e cinco homens que se encontravam a bordo da escuna, comandados pelo contramestre Joaquim Neto, lutaram contra os ingleses por cerca de três horas, com o apoio do traficante cabofriense. Vitoriosos, os ingleses conduziram a escuna para a frente de seu trapiche e "deitaram-lhe fogo" ${ }^{20} \mathrm{~A}$ embarcação militar inglesa somente abandonou o local às $21 \mathrm{~h}$. A população e as autoridades locais foram testemunhos de tão "revoltante insulto", quando a bandeira brasileira foi cortada em tiras pelo oficial inglês, ao som de ipes e urrahs. Segundo Gonçalves, o episódio ocorrido com a Rival obedecia a ordens diretas de Euzébio que Queiroz, como um ato de vingança pessoal contra ele. ${ }^{21} \mathrm{~A}$ resistência ao fim tráfico não estava limitada apenas às tentativas contínuas de desembarques de negreiros no litoral, mas resultava também de uma clara demonstração de autoridade por parte de homens de negócios que não admitiam o seu fim. Essa demonstração de força e poder ensejava até mesmo a formação de contingentes paramilitares por parte dos traficantes, para enfrentar interesses contrariados.

Essas intervenções britânicas serviram para uma série de interpelações ao Conselho de Estado, que não se pronunciava a respeito. ${ }^{22}$ Pouco menos de dois meses antes da vigência da lei, em 23 de junho de 1850, o brigue-escuna brasileiro Polka, fundeado no porto de Macaé, próximo à fortaleza local, foi interceptado por dois escaleres do vapor de guerra inglês Sharpsshooter. Oficiais ingleses pediram os passaportes do navio, não obtendo resultados. Voltaram uma hora depois, com a presença do comandante da embarcação britânica, exigindo pela segunda vez tais documentos, dessa vez apresentados pelo comandante da embarcação

\footnotetext{
${ }^{20}$ Diário do Rio de Janeiro, ano XXIX - Rio de Janeiro, quinta-feira, 4 de julho de 1850, n. 8.437, p. 3. Novas transcrições dos fatos foram feitas por José Gonçalves no Correio Mercantil, Rio de Janeiro, 23 de junho de 1859, e no Jornal do Commercio, Rio de Janeiro, 8 de agosto de 1962.

21 "José Gonçalves da Silva à nação brasileira", Jornal do Commercio, Rio de Janeiro, 23 de junho de 1863.

${ }^{22}$ Diário do Rio de Janeiro, Rio de Janeiro, 15 de julho de 1850, n. 8.446, p. 2.
} 
brasileira. De noite, os ingleses retornaram e atracaram ao Polka, trancaram os tripulantes e largaram as amarras em direção a Cabo Frio, onde alastraram o navio, de propriedade de Antônio Leopoldino Ribeiro, suposto traficante de Barra de São João. ${ }^{23}$ No dia 18 de junho, esse mesmo vaso de guerra inglês interceptou a sumaca Malteza, com destino a Cabo Frio, afundada na madrugada do dia seguinte próximo a Maricá, "sob as barbas" da Fortaleza Santa Cruz, em Niterói. Cinco dias depois, os ingleses desembarcaram a tripulação da embarcação na praia de Santa Luzia, no Rio de Janeiro. Quem, no dia seguinte, transmitiu pessoalmente essa informação ao jornal Correio Mercantil, do Rio de Janeiro, foi Felix Antunes Moreira, genro de José Gonçalves, provavelmente, uma das "várias pessoas da praça" que estavam na embarcação, podendo ser até mesmo um dos tripulantes da Malteza. Vale registrar que essa informação ao jornal da Corte partiu de um crítico das ações dos ingleses, que apelava ao chavão nacionalista para desqualificar a perseguição britânica. ${ }^{24}$ Dessa forma, a lei do fim do tráfico, quando posta em prática, foi sob uma intensa marcação da Grã-Bretanha, que não se intimidava em tomar a dianteira na repressão, conflitando com negociantes e autoridades brasileiras.

Sobre os atos de beligerância dos ingleses impõem-se duas considerações sobre a lei de 4 de setembro de 1850: a pressão inglesa, tradicionalmente vista pelo seu duplo sentido imperialista/humanitário, passa a ter cores de um ultimato militar, pelas seguidas intervenções de guerra contra embarcações brasileiras envolvidas no tráfico. Por outro lado, sugiro que os próprios traficantes empurravam a situação ao seu limite, uma vez que suas embarcações encontravam-se protegidas pelas fortificações do litoral, como em Cabo Frio e Macaé, para citar os exemplos mencionados, importantes pontos de desembarque no período. Devem ser levadas em conta as desconfianças que pairavam sobre os comandos dessas unidades militares, pelas suas aproximações com o tráfico, como já havia alertado o Ministério da Justiça, em face das "grossas pitanças" distribuídas a essas autoridades, levando-os ao êxtase pela chegada de um navio negreiro, quando "suspirariam pela salvação". Tais revelações foram feitas por José Gonçalves em carta ao impe-

\footnotetext{
${ }^{23}$ Jornal do Commercio, Rio de Janeiro, 27 de junho de 1850, n. 174, p. 2.

${ }^{24}$ Correio Mercantil, Rio de Janeiro, 24 de junho de 1850.
} 
rador. ${ }^{25}$ Portanto, ao lado dos homens de "grosso trato" estavam aqueles que recebiam fartas propinas por pactuar com o comércio ilegal de africanos.

A escuna Rival, atacada pelos ingleses em Cabo Frio, próximo ao trapiche de José Gonçalves, era propriedade de Francisco Gonçalves Lages e fora identificada como uma embarcação equipada para o tráfico de africanos. O que restou dela, depois de lançado nos autos de apreensão, feito pelo juiz de Órfãos de Cabo Frio, foi entregue a José Gonçalves da Silva, nomeado curador e fiel depositário dos destroços e dos equipamentos da escuna. ${ }^{26}$ José Gonçalves também atuava no segmento de construção e reforma de embarcações recuperadas ao longo da costa fluminense. Muitos desses equipamentos e peças tinham vestígios de utilização na infraestrutura destinada ao tráfico, principalmente aquela voltada à construção e recuperação dos navios negreiros. O comerciante tinha o privilégio de arrematar peças ou embarcações, chegando mesmo a ser nomeado, pelas instâncias judiciais locais, responsável pela custódia desses materiais, incluindo os destroços de embarcações. Por isso foram parar no trapiche de Gonçalves os equipamentos do brigue/bergantim Lúcifer. Depois de sair da província do Espírito Santo com destino a Bombaim, na Índia, via Zanzibar, passados 71 dias de viagem, a embarcação fora atingida por "inúmeros contratempos" e temporais sucessivos. O capitão Vitor da Silva Freira, com a embarcação fazendo água e com vários doentes a bordo, depois de registradas cinco mortes, quando estava próximo ao Cabo da Boa Esperança, resolveu "arribar" ao primeiro porto do Brasil, Cabo Frio.

Negociante plural, ligado aos negócios do mar, José Gonçalves teve arrestado os bens que estavam no seu barracão, no seu trapiche e em seu estaleiro, uma vez

\footnotetext{
${ }^{25}$ Carta aberta ao imperador Pedro II, publicada no Jornal do Commercio, Rio de Janeiro, 20 de janeiro de 1862 .

${ }^{26}$ Junto com os destroços da escuna Rival estavam relacionados os seguintes equipamentos: "1 bote de 23 palmos de cumprimento e 6 de boca, 2 mastros inutilizados, 1 gurupés de pinho queimado e pão de bijarrona, 1 ferro grande e 1 corrente, 1 verga grande de pinho, 120 lingados de ferro, com lastro, 2 vãos de mastro, 2 pegas de vão do mesmo pão, 16 arrobas de folhas e pedações de cobre, ferros, chapas, covilhãs velhas, com peso de 28 arrobas, 109 moitões, cadernozinhos de diferentes tamanhos, 1 insárcia grande queimada, de linho, 1 estae de bijarrona em bom estado, 1 estae grande de traquete, 2 moitões de retranca do vargueiro, 1 estae da giba, 1 patarraz do pão de bijarrona, 1 dito da patarraz de pica-peixe, 2 estribeiras do pão de giba, 1 colhedor de incárcia do traquete, 2 brandões do joanete, 1 brandal de gávia, 2 amantilhos do mastro grande, 1 funda de inçar pipas, 1 estaga de velacho, 24 arrobas de cobre velho".
} 
que pairava sobre ele e suas propriedades, na cidade de Cabo Frio, a certeza de serem casas de negócios ligadas ao tráfico de africanos.

\section{O traficante e o ministro}

José Gonçalves da Silva apostava que Eusébio de Queiroz representava determinadas facções que, ao tomarem conta do poder, "avassalavam a propriedade, os costumes e as leis", classificando-as como "abutres da anarchia". Para reforçar seus argumentos, Gonçalves anexara ao Libello que publicara a descrição de 24 documentos que atestavam, segundo ele, a lisura de seus negócios, o caráter e as virtudes de um "homem bom", cuja contribuição fora destacada na luta pela emancipação nacional e revelara-se na mais providencial figura que protegia a cidade e a população de Cabo Frio. Autoridades ou não atestavam suas qualidades de empreendedor, de homem solidário e de boa vontade. Calejado nos negócios atlânticos, Gonçalves prestava ajuda e socorro aos navegantes. Foi o principal patrocinador da visita do imperador Pedro II a Cabo Frio, mandando organizar um banquete ao monarca em Arraial do Cabo, oferecendo fogos para recepcioná-lo. Patrocinou as artilharias do Forte São Mateus e Sururu, a pedido do comandante, Francisco José da Silva, oferecendo 20 homens que trabalhavam em seus armazéns e embarcações. Gonçalves cedeu víveres e proteção para as corvetas Bertioga e Euterpe, quando da visita do presidente da província, Aureliano de Souza Azevedo Coutinho, à cidade, em 1846. Nas epidemias que ocorriam, como a de febre amarela, em 1849, o negociante cedeu seus armazéns da barra, além de embarcações, para "acolher os aflitos", transformando seu trapiche em um lazareto. A tudo se prestava o auxílio do grande negociante, homem necessário para "todas as urgências". Cada manifestação de ajuda, solidariedade ou filantropia prestada por José Gonçalves da Silva materializava-se em um documento, subscrito por inúmeras pessoas, em Cabo Frio e no Rio de Janeiro, para ser anexado ao Libello. "Como poderia esse homem ser alvo da mais injusta vingança?", indagava o próprio manifesto.

Inocentado, mas permanecendo com seus bens confiscados e indisponíveis, José Gonçalves da Silva moveu uma luta permanente e sem tréguas pela restituição desses bens - em destaque, as mercadorias dos armazéns e do trapiche. Ao que sabemos, passados 12 anos, Gonçalves ainda investia pesadamente na divulgação do memorial dos acontecimentos de 1851, que fez publicar em jornais da 
Corte e em similares portugueses. Longas cartas, artigos e documentos escritos em sua defesa tornaram-se públicos, incluindo as correspondências dirigidas ao imperador Pedro II. Esse conjunto era parte das suas estratégias para reaver seus bens. Os pontos que mais se destacam são as críticas à intromissão dos ingleses em face da soberania nacional e, sobremaneira, os ataques a Euzébio de Queiroz, de uma forma contundente e agressiva, levando o próprio detratado a se posicionar publicamente em relação ao seu desafeto.

Gonçalves não se conformava com os prejuízos que lhe haviam sido impostos pelo governo. Toda a carga de responsabilidade recaía sobre Euzébio de Queiroz. Mesmo com parecer favorável do Conselho do Estado, o traficante não conseguiria reaver seus bens. "Há 12 anos mendigo nas secretarias se me passe por certidão à ordem de quem foram meus bens sequestrados, e há 12 anos ou os ministros me voltam as costas, ou põem em todos os meus requerimentos - indeferido - não tem lugar." ${ }^{27}$ "Esbulhado" de seus bens, por ordem de Euzébio de Queiroz, Gonçalves reclamava de todo o tipo de arbitrariedade cometido contra um homem que lutava contra "terríveis privações". ${ }^{28}$ Em uma das dezenas de cartas dirigidas À Nação Brasileira, de 1864, editada pela Imprensa da Universidade de Coimbra, Gonçalves lembrava sua absolvição criminal em 15 de fevereiro de 1853, porém, decorridos 12 anos, seus bens ainda permaneciam indisponíveis, por "perseguição e injustiça". Oprimido e "vexado", Gonçalves recordava que sua única saída fora recorrer ao Legislativo brasileiro para reaver seus bens e se ressarcir de seus prejuízos: "este foi o preço pago por quem foi imolado como vítima para dar satisfação aos insultos praticados debaixo das fortalezas desse Império pelos cruzadores ingleses" ${ }^{29}$

No parlamento do império, a primeira casa que recorreu foi ao Senado. Poucos senadores, como o barão de Pindaré, Antônio Pedro da Costa Ferreira, contestavam os efeitos da "tirania, da prepotência, do arbítrio e da vingança" que se aplacavam sobre o traficante de escravos. Entretanto, as palavras do senador

\footnotetext{
27 "XII aniversário do sequestro mandado fazer em todos os meus bens e propriedade, na cidade de Cabo Frio, pelo ministro dos negócios da Justiça de 1851", Jornal do Commercio, Rio de Janeiro, 20 de janeiro de 1862 .

${ }^{28}$ Carta dirigida ao imperador Pedro II, em 13 de novembro de 1865, depois de 14 anos da apreensão de seus bens. Biblioteca Nacional - Setor de Manuscritos II - 32, 10,7.

29 "José Gonçalves da Silva à nação brasileira", Coimbra, Imprensa da Universidade, 1964. Biblioteca Nacional, Setor de Manuscritos II - 32, 10,7.
} 
foram encerradas ao silêncio imposto aos taquígrafos. A "esponja do poder" teria suprimido aquelas primeiras palavras, colocando sob censura a fala do parlamentar na tribuna. Mas Pindaré insistiria em denunciar o tratamento dado a Gonçalves até que alcançasse os principais jornais da Corte. A defesa mais veemente de Gonçalves veio, no entanto, do deputado mineiro Mello Franco, ao expressar sua repulsa ao caso diante do delegado Azambuja, que ocupava também uma vaga de deputado. Azambuja, principal ator da repressão policial no confisco de Cabo Frio, constrangeu-se diante de um Mello Franco incisivo na defesa de José Gonçalves, não do traficante, mas de alguém que, sozinho, vinha pagando caro pelo seu crime, diante de outras figuras do mesmo ramo, que até então não teriam sido incomodadas, pelo menos no tocante ao confisco de patrimônio. Perguntava Mello Franco por que somente José Gonçalves estaria sofrendo os "arbítrios e as injustiças", se outros traficantes tão bem conhecidos por todos andavam impunemente pelo país. "Onde estariam os Breves? E os outros traficantes de regiões próximas a Cabo Frio, como Rio das Ostras, Barra de São João? Onde estariam aqueles que compraram os 526 africanos trazidos pelo brigue Sagaz?” Todos eram conhecidos pela polícia, por praticarem o "comércio infame".

Azambuja mostrava-se lacônico e tergiversava nas respostas às indagações de Mello Franco. Tornara-se patente para o deputado o tratamento diferenciado dado aos traficantes depois da lei de 1850, tomando como bandeira o caso de José Gonçalves da Silva: "a espada da justiça só encontrou senão a ele", diria Franco. Por outro lado, Azambuja insistia em desqualificar a imprensa pelo tratamento que vinha sendo dado ao caso José Gonçalves. Entretanto, não explicava por que vivendo o traficante em Cabo Frio, o segundo maior plantel escravista da província, na década de 1840, atrás somente de Campos dos Goytacazes, ${ }^{30}$ uma região povoada de pessoas envolvidas no tráfico, inclusive autoridades, somente Gonçalves sofreria com a larga punição. Franco insistia em questionar o antigo chefe de polícia pelo fato de não ter tido o mesmo procedimento com outros traficantes naquelas paragens. Todos estavam materialmente impunes. Interpelado, o policial-deputado Azambuja contestava que tivesse havido qualquer tipo de parcialidade ao conduzir o processo de José Gonçalves da Silva, da mesma forma que sugeria ser imparcial a defesa que Mello Franco fazia de José Gon-

${ }^{30}$ Maria de Fátima Silva Gouvêa, O império das províncias, Rio de Janeiro, Civilização Brasileira/ Faperj, 2008, p. 43-44. 
çalves. Mesmo que o Conselho de Estado tivesse decidido em seu favor, e ainda o fato de que a "vítima", assim chamada por Mello Franco, estivesse sob a órbita dos saquaremas, ${ }^{31}$ tudo isso, não seria o bastante para livrar Gonçalves de sofrer a "mais atroz perseguição".

O negociante começara a demonstrar a partir daí a sua séria desconfiança das motivações particulares para a perseguição implacável que sofria por parte de Euzébio de Queiroz, especialista em "cultivar as desgraças regadas para brotarem mais depressa pela mão piedosa de um filho da África”, em uma clara menção às origens de Queiroz. ${ }^{32} \mathrm{O}$ ministro, segundo Gonçalves, não poderia ser amigo do Brasil, pois "é africano". O negociante de escravos insinuava, por vezes, o envolvimento do próprio Euzébio de Queiroz no tráfico, pois, se não houvesse a tamanha guerra pelo seu fim, o ministro da Justiça faria do país uma "colônia da África". ${ }^{33}$

José Gonçalves da Silva seria, também, reconhecido como vítima em Portugal. O Diário do Rio de Janeiro reproduziu um artigo (ou panfleto) publicado no periódico português $\mathrm{Da}$ Revolução de Setembro, de 25 de abril de 1861, que reforçava as injustiças cometidas contra José Gonçalves no conjunto das pressões inglesas pelo fim do tráfico. É instigante observar que um jornal luso tenha tido interesse em fazer referências ao fim do tráfico e à defesa de um traficante brasileiro, com críticas ao governo de Pedro II em se "apequenar diante dos ingleses". Curioso, também, era o fato de um texto português revelar, sem rodeios, os negócios de Gonçalves com o tráfico. Dizia o jornal:

O Império do Brasil passou por uma destas crises violentas quando, obrigado pelo governo britânico, se viu na necessidade de acabar repentinamente com o tráfico da escravatura, de que tanto dependia a agricultura da nação brasileira: e pode-se dizer que, apesar da ilustração e solicitude do governo do Brasil, empregando por todos os modos e com os maiores sacrifícios os mais convenientes para promover a emigração da raça branca da Europa, ainda até se não pôde vencer essa terrível crise, faltando imensos braços à agricultura...

\footnotetext{
${ }^{31}$ Mello Franco refere-se ao grupo político homogêneo que liderou o regresso conservador de 1937, forçando uma coalizão política em prol da centralização do poder. Ver Ilmar R. Mattos, O tempo Saquarema. A formação do Brasil império, São Paulo, Hucitec, 1987.

${ }^{32}$ Sessão do Parlamento de 10 de julho de 1852, transcrita por José Gonçalves da Silva em seu Libello.

33 "José Gonçalves da Silva à nação brasileira”, Jornal do Commercio, Rio de Janeiro, 5 de junho de 1863.
} 
Como a escravatura antes do tratado de 1850 era tolerada naquele país, muitos negociantes, e entre eles José Gonçalves da Silva, tinham importantes estabelecimentos nas costas marítimas daquele Império, para receber os escravos da Costa da África.

O governo brasileiro, apertado e perseguido pelo governo britânico, sofrendo os maiores insultos debaixo de suas fortalezas, viu-se na necessidade de dar um exemplo, e de tomar medidas rigorosas, satisfazendo o governo inglês. Tal é sempre a triste condição das nações pequenas!

Escolheu para vítima o cidadão José Gonçalves da Silva e um belo dia os empregados do governo caíram sobre o seu grande estabelecimento, em Cabo Frio, invadiram-lhe tudo, levaram-lhe para cima de setenta escravos, que o governo ainda hoje possui, trouxeram para o Arsenal de Marinha do Rio de Janeiro todos os aparelhos e barcos daquele estabelecimento, que ficou completamente aniquilado e entregue ao abandono e à pilhagem. ${ }^{34}$

Nesses termos, o tráfico inspirava inúmeras redes de proteção que ultrapassavam as fronteiras do império. Especialmente no caso de José Gonçalves, torna-se emblemático que a expropriação de parte da sua fortuna tocasse os brios dos interesses portugueses no Brasil, "contra os quais com tanta energia e consciência bradaram na câmara dos pares de Lisboa os respeitáveis Conde de Taipa e o Marquês de Vallada".

Uma das suposições levantadas pelo próprio traficante para tentar entender o porquê de tamanha perseguição seria o fato de ele ter tido transações com um homem poderoso e rico, de quem era credor de uma soma "avultada", bem relacionado com Euzébio de Queiroz. Sentindo-se na condição de proscrito, José Gonçalves temia que seus créditos fossem dados por liquidados, e o "opulentíssimo ficava ainda mais opulento". Trata-se, aqui, do comendador José Antônio dos Guimarães, sócio de José Gonçalves, que "não tinha outro negócio que não fosse o tráfico de africanos" e nada sofreu. Guimarães foi também presidente da Câmara Municipal de Cabo Frio, entre 1850 e 1851, quando Gonçalves foi preso. Não há nos Livros de Atas da instituição nada que diga respeito aos fatos acontecidos na cidade naqueles dias de 1851. Há, sim, um grande hiato, sem qualquer registro, entre 20 de janeiro e o reinício das sessões da Câmara no mês de março daquele ano. Tudo leva a crer que a cidade tenha sido sitiada; a população, amedrontada e paralisada pelas tropas vindas da Corte. Imune, Guimarães "banque-

\footnotetext{
${ }^{34}$ Diário do Rio de Janeiro, 25 de maio de 1862.
} 
teara-se" com Azambuja, o chefe de Polícia, depois de este último cumprir sua missão de abarrotar o vapor $D$. Affonso com os bens confiscados do negociante José Gonçalves.

Seu sócio nada sofreu. Sua dívida com Gonçalves batia o montante de 131 contos de réis. Este tinha certeza de que Guimarães teria interesse em tirar proveito de tal situação, pois assim não haveria de ajustar contas com Gonçalves. No entanto, para aplacar as angústias do sócio traficante, Guimarães, antes de morrer, em 1856, deixaria registrada em seu inventário a dívida com Gonçalves. O temor inicial de José Gonçalves justificava-se, pois a pingue herança de Guimarães, segundo o traficante cabofriense, vinha sofrendo investidas "por certos felizes, bem conhecidos nessa Corte, que têm costume comprarem por dez o que valia cem". O negociante referia-se a José Frazão de Souza Breves, Bernardo Alves Correa de Sá, além de Joaquim Alves Correia, procurador de Tereza de Jesus dos Guimarães, viúva do devedor. Os três eram vistos por Gonçalves como "golpistas" ao tentarem liquidar uma herança de 1.500 por 80 contos de réis. ${ }^{35}$ Gonçalves, então, providenciou embargos aos tribunais para conseguir uma precatória e fazer jus ao valor que lhe era devido pelo "opulento capitalista" Guimarães: "meu sócio não se poupou de sacrifícios e bajulações, e foi tão feliz que não conseguiu ajustar contas comigo, devendo-me cento e trinta e um contos de réis, como já provei nos tribunais do país" ${ }^{36}$ Constata-se, pois, nessa época, o trânsito de grandes fortunas por Cabo Frio. Tratava-se de uma importante região voltada para a pesca, para a produção de gêneros alimentícios, destacando-se a atividade salineira, embora ainda sem a expressão das áreas da produção cafeeira e açucareira. Ainda assim, somos instados a deduzir que a presença desses homens, como José Gonçalves da Silva e José Antônio dos Guimarães, em Cabo Frio e em outras cidades situadas em uma região de grandes enseadas, próprias à atracação de embarcações, está intimamente ligada aos negócios do tráfico. Logo, podemos pensar na integração dessas baixadas litorâneas da porção atlântica do norte do Rio de Janeiro à lógica do capital mercantil que integrava a sociedade escravista fluminense.

\footnotetext{
35 "Recordações históricas de Cabo Frio", Correio Mercantil, Rio de Janeiro, 23 de junho de 1859, e transcrito no mesmo jornal em 8 de agosto de 1862. Biblioteca Nacional - Setor de Manuscritos II $-32,10,7$.

36 “Carta à nação brasileira", Jornal do Commercio, Rio de Janeiro 20 de janeiro de 1863.
} 
José Gonçalves, em seus artigos publicados na Corte, reforçava sua indignação ao tratamento especial dado por Euzébio de Queiroz ao seu sócio José Antônio dos Guimarães. Não admitia sua exclusão do processo em que estava envolvido, sabido dos seus amplos negócios no tráfico de africanos. O traficante via nisso mais uma evidência da estreita relação que ligava Guimarães ao ministro da Justiça, em especial "naquele negócio da Campos Novos", e de uma Carta de Seguros em que deu privilégios a Guimarães. Luiz Henrique Dias Tavares chama a atenção para os negócios que envolvem apólices de seguros, que davam cobertura à carga e igualmente aos escravos no tráfico atlântico. ${ }^{37}$ Campos Novos era a antiga fazenda jesuítica localizada na confluência dos municípios de Cabo Frio, São Pedro da Aldeia e Barra de São João, cuja história perpassa por uma série de conflitos agrários. A veemência dos ataques de Gonçalves a Queiroz deixa margem para especular sobre a própria participação do ministro nos negócios do tráfico. Para José Gonçalves, o poder de Euzébio de Queiroz imobilizava qualquer ação contrária:

Mas o poder do Sr. Euzébio absolveu-o antes de ser acusado. É muito bom ser amigo do Sr. Euzébio. Seu eu fora não estaria hoje no desembolso de oitocentos e tantos contos de réis que S. Exa. mandou que me fossem tirados. [...] Há 13 anos sofro privações, há 13 anos peço justiça sem que ainda ela me tenha sido concedida; há 13 anos reclamo a reparação do mal que o senhor Euzébio me causou, mas nada tenho podido conseguir, porque o senhor Euzébio ainda faz uso das pílulas do diabo. ${ }^{38}$

Não cessava sua insistência em cobrar de Euzébio de Queiroz a retomada de seus bens. Para Gonçalves, Queiroz seria o principal "autor de seus males", por ter mandado sequestrar seus bens. Contando que Euzébio de Queiroz estivesse satisfeito por seu infinito sofrimento, Gonçalves reiterava continuamente que o ministro da Justiça lhe estendesse a mão. Euzébio respondeu a José Gonçalves considerando as suas suspeitas como injuriosas, hostis e desprovidas do menor sentido. "Que motivos teriam para persegui-lo?" Euzébio considerava que Gonçalves estaria sendo induzido a detratá-lo com base em intrigas. ${ }^{39}$ Mais tarde, Gonçalves radicalizaria ao acusar Euzébio de "prepotente e ladrão", além de lamentar o fato de que a legislação criminal brasileira jamais serviria para

\footnotetext{
${ }^{37}$ Luiz Henrique Dias Tavares, op. cit., p. 18.

38 “Carta à nação brasileira”, Jornal do Commercio, Rio de Janeiro, 20 de janeiro de 1863.

${ }^{39}$ A carta e a resposta são de 8 e 9 de dezembro de 1960, respectivamente.
} 
condená-lo, pois nas rodas do poder fatalmente seria considerado um "sacrilégio" levá-lo ao banco dos réus. ${ }^{40} \mathrm{O}$ próprio Gonçalves afirmaria, posteriormente, que Euzébio de Queiroz havia lhe revelado, em certa ocasião, que sua conduta no caso foi para "oferecer ao governo britânico, em sacrifício, uma vítima brasileira", franqueza utilizada pelo ministro quando da visita que fez à casa que Gonçalves matinha no Rio de Janeiro, à Rua Nova do Imperador, n⿳0 107, vizinho que era do conselheiro de Estado. Este teria lhe confidenciado que "foi o ministro inglês Hudson que exigiu de mim a sua perseguição, por causa do conflito que houve em Cabo Frio, quando o vapor inglês Carmorant lá foi incendiar a escuna Rival". ${ }^{41}$ James Hudson era ministro plenipotenciário inglês no Brasil e havia alertado lorde Palmerston, desde 1848, que o tráfico negreiro no Brasil era controlado por uma minoria de capitalistas portugueses, considerados os homens mais ricos do país. ${ }^{42}$ Em outra carta que havia escrito a Euzébio de Queiroz, Gonçalves sugeria que a perseguição "bárbara e atroz" que vinha sofrendo teria relação com as eleições de 1844, que consagraria a montagem de um gabinete liberal.

O negociante/traficante, durante todos esses anos, não se cansou de responsabilizar Euzébio de Queiroz pela sua destruição. Mais uma vez, no Jornal do Commercio de $1^{\circ}$ de junho de 1863, Gonçalves apresentou fatos que sustentavam o "padrão de glória do Conselheiro Euzébio". Para ele, o silêncio de Euzébio não era compatível com a imagem de "ilustre estadista, revestido da coragem [de] que era dotado". Causador dos males do negociante, Euzébio de Queiroz passou a ser denunciado por Gonçalves de estar "carregado de crimes", que se escondiam atrás da sua autoridade, ao utilizar-se dos seus "satélites". Além do mais, Euzébio de Queiroz, desde sua chegada ao Brasil, em 1824, sempre havia vivido do Estado, diferentemente de Gonçalves, vindo para o país em 1813, cuja fortuna construiu "sem depender dos frutos da nação". Euzébio não poderia dizer o mesmo, em contraste com o outro, que sustentava que havia "tudo ganho com o suor do seu rosto”. Em certos momentos da sua batalha travada contra Euzébio de Queiroz, sustentava, também, sua condição, a de "brasileiro", em oposição à alcunha de

\footnotetext{
40 “Carta à nação brasileira”, Jornal do Commercio, Rio de Janeiro, 20 de janeiro de 1863.

41 “O cidadão José Gonçalves da Silva à nação brasileira”, Jornal do Commercio, Rio de Janeiro, 16 de maio de 1863.
}

${ }^{42}$ Luiz Henrique Dias Tavares, apud Lloyd, op. cit., p. 26. 
"filho da África", forma depreciativa com que se referia a Euzébio de Queiroz, como uma maneira de caricaturar o ministro do império.

Gonçalves acusava Euzébio de atuar nos bastidores, com palavras "adubadas de hipocrisia". Tratava-se, segundo ele, de um homem "poderoso e vingativo". Assim, Euzébio de Queiroz teria participado ativamente de sua prisão para que fosse confundido na cela com salteadores e assassinos: "foram $500 \$ 000$, que dei ao honrado carcereiro. Que justiça, que moralidade, que país". ${ }^{43}$ Euzébio de Queiroz, conselheiro de Estado, senador do império, presidente da Relação da Corte, inspetor-geral da Instrução Pública, chefe de polícia da Corte, era considerado por seu contendor como um "feitor da potência inglesa, fraco e cheio de humildade para com o governo inglês" ${ }^{44}$ As rusgas e os desentendimentos entre os dois parecem ter chegado ao limite em uma discussão em frente à Igreja dos Ingleses, na rua dos Barbonos, quando Gonçalves estava de partida para Cabo Frio. Desde então, teriam sido iniciadas as perseguições, por promessas feitas pelo ministro da Justiça em não perdê-lo de vista. Parece que Gonçalves e Queiroz eram figuras próximas, que passaram a ter desavenças e falas contraditórias em tons mais enérgicos, quando nos aproximamos da vigência da lei. O Relatório Alcoforado, citado por Luis Henrique Dias Tavares, destaca, por exemplo, a convocação feita por Euzébio de Queiroz para uma reunião com os principais traficantes da praça, para lhes falar dos possíveis efeitos que deveriam resultar da aplicação da referida lei. ${ }^{45}$ Tudo leva a crer que o ministro privasse de certa intimidade, em um concerto de mercadores de escravos do Rio de Janeiro, em meados do século XIX.

Mantido sob expressa vigilância em seus deslocamentos do Rio de Janeiro para Cabo Frio, o negociante José Gonçalves fora impedido de atuar na navegação de cabotagem sem a necessidade de apresentar passaporte, condição de que até então estava dispensado. Euzébio de Queiroz o teria privado do direito de não portar o documento como parte do plano para alcançá-lo em suas viagens. Decisão premeditada, a exigência foi determinada pelo chefe de polícia da Corte, Francisco Diogo Pereira de Vasconcelos, em 9 de janeiro de 1851, portanto 11

\footnotetext{
43 "José Gonçalves da Silva à nação brasileira". Jornal do Commercio, Rio de Janeiro, 5 de junho de 1863.

44 "José Gonçalves da Silva à nação brasileira", Jornal do Commercio, Rio de Janeiro, 29 de julho de 1863.

${ }^{45}$ Luiz Henrique Dias Tavares, op. cit., p. 122.
} 
dias antes do assalto aos seus bens em Cabo Frio. Portando o passaporte, José Gonçalves deixou a Corte no vapor Macaense, em 14 de janeiro de 1851, em direção à cidade. No seu encalço, partiu o vapor D. Affonso, no dia 18 de janeiro de 1851, a mais moderna e veloz fragata da Armada brasileira, fabricada na Inglaterra, que chegara ao Brasil dois anos antes, em 1849. Vale especular se o pacote inglês contra o tráfico poderia até mesmo incluir a renovação da força naval brasileira para cercar os negreiros na costa. No dia 20 de janeiro, a embarcação militar chegaria com as tropas e policiais a Cabo Frio, virando de ponta-cabeça a vida do negociante José Gonçalves da Silva.

Fui perseguido em 1851 com o pretexto de que eu era traficante de africanos quando em tal época tal comércio não existia; e ainda mesmo que eu antes me tivesse dado a ele, porque era tolerado nessa ocasião; eu não tinha culpa alguma, porque sendo Brasileiro, e sabendo da proibição expressa da importação desse gênero, respeitador como era e como sou das leis do meu país, certamente não teria procurado infringilas. Além de que, eu tinha fortuna tanta quanto me era necessário para viver com honra e honestidade. ${ }^{46}$

\section{Considerações finais}

Ao considerar a possibilidade de transformar-se em um proscrito, depois de tudo o que lhe aconteceu, o traficante fluminense, obedecendo aos preceitos morais da sociedade brasileira do século XIX, fora introduzido no processo de conversão, na concepção de Jaime Rodrigues, ${ }^{47}$ experimentado por alguns homens do extinto tráfico. Nosso traficante deveria ter pleno conhecimento desse processo, ao revelar-se, dentro dele, conhecedor do significado de uma regressão social. Teria passado até aqui por duas prisões. Essa regressão transportaria José Gonçalves da condição de comerciante rico, homem abastado, senhor de todos e de tudo, para os limites do mundo da desordem, reconhecido como pirata, voraz e indigno de morar no país, como aconteceu com alguns de seus pares, citados no início deste texto. Ainda assim, Gonçalves procurava colocar em teste sua reputação, ao solicitar e ter concedidos por parte do visconde do Uruguai e do

\footnotetext{
46 "José Gonçalves da Silva à nação brasileira", Jornal do Commercio, Rio de Janeiro, 5 de junho de 1863.

47 Jaime Rodrigues, op. cit.
} 
visconde de Sepetiba privilégios em ser escoltado por policiais nos trajetos e em suas estadas em Cabo Frio, por receio de ser assassinado.

Em determinado momento, enquanto Paulino José Soares de Souza e Aureliano de Souza e Oliveira Coutinho, os dois saquaremas, na qualidade de presidentes da província do Rio de Janeiro, o reconheciam como portador de autoridade e prestígio, por considerá-lo um "homem honesto" e "negociante importante", nas palavras do próprio visconde do Uruguai, José Gonçalves poderia contar com o amparo da polícia e da Justiça, os braços fortes do Estado.

O que teria acontecido a José Gonçalves da Silva, depois desses anos todos, ainda não se sabe. É preciso avançar. Independente disso, Gonçalves tinha firme consciência do custo que lhe saltou o fim do tráfico no Brasil e o que ainda poderia lhe custar. Sua expressão mais enfática em que reconhecia as contradições dessa conversão social no país em que viveu aparecia quando afirmava que da condição de cidadão honesto transformaram-no em um cidadão criminoso, fronteira apenas reconhecida por um traficante brasileiro depois da lei de 1850. Honesto enquanto durou seu vasto negócio com a África; criminoso apenas quando o vasto negócio ilícito cessou. Seu jargão preferido, repetido centenas de vezes em seus textos, para revelar sua irritação com os novos tempos, era: "Que moralidade! Que justiça! Que país!”48 Pelos menos poderia tê-lo utilizado para batizar um dos seus barcos entre santos e demônios.

48 "José Gonçalves da Silva à nação brasileira", Jornal do Commercio, Rio de Janeiro, 5 de junho de 1863. 